\title{
Cristina Bacchilega, Postmodern Masallar: Toplumsal Cinsiyet ve Anlatı Stratejileri (Postmodern Tales: Gender and Narrative Strategies), Çev. Fatma Büşra Helvacıŏlu, İstanbul: Avangard Kitap, 2016, $263 \mathrm{~s}$.
}

Ayşe Dilara Bostan*

Masallar, genel kabule göre çocukları muhatap alan metinler olarak görülür. Fakat farklı coğrafyalarda gezmiş, gezdiği toprakların sosyal, kültürel ve sınıfsal kabullerini küfesine atmış çok katmanlı anlatılardır. Sözlü kültür geleneğinin bir parçası iken anlatıldığı topraklara dair otantik bilgileri "anaerkil” ögeler ile birlikte sunan masallar, edebî bir tür olarak kanonlaşma evresinde sınıfsal öğelerin yanı sıra kadına ve erkeğe dair stereotipik temsilleri de bünyesine katarak dönüşmüştür. Bununla birlikte yaşayan bir tür olarak masal, uzun süredir hem edebî yazında hem de görsel kültürde postmodern öğeler ile harmanlanarak yolculuğuna devam etmektedir.

Günümüzde edebî metinlerin yanı sıra animasyonlarda, dizilerde, sinema filmlerinde ve daha pek çok platformda masalların klasik ve postmodern versiyonları ile karşılaşıyoruz. Pek çokları için masalların en bilindik versiyonlarının masum mu yoksa zararlı mı olduğu hâlihazırda bir soru işaretiyken; bu anlatı türünün giderek giriftleşen postmodern versiyonları kafa karışıklığını daha da arttırmaktadır. Cristina Bacchilega'nın 1997 yılında kaleme aldığı, Türkçe'ye ise 2016 yılında kazandırılan Postmodern Masallar: Toplumsal Cinsiyet ve Anlatı Stratejileri adlı eseri, tam da bu bağlamda ilgili okuyucuya kılavuzluk eden bir çalışmadır. Folklor, geleneksel anlatılar, toplumsal cinsiyet ve postmodern anlatı stratejileri

* Arş. Gör. Dr. Dilara Bostan, Marmara Üniversitesi, İletişim Fakültesi, Radyo Televizyon ve Sinema Bölümü, İstanbul, Türkiye, e-mail: dilaraokuyucu@gmail.com 
alanlarında çalışmalarını sürdüren Bacchilega, bu yazının inceleme konusunu oluşturan eserinde masalı anlatısal olarak geçirdiği dönüşümlerin yanı sıra toplumsal cinsiyet rollerinin sunumu bağlamında da merkezine alır. Eser, masala dair gerçekleştirilen akademik çalışmalar arasında sunduğu çok yönlü okumalar ile ilgili literatüre önemli bir katkı sağlar.

Masalların günümüzde nasıl dönüştüğüne dair sarih bir kavrayış peşinde olduğunu söyleyen Bacchilega, özellikle anlatı kurallarının nasıl yeniden üretildiğini ifadeye kavuşturmak peşindedir. Bunun için "klasik" anlamdaki masalları yeniden yazan ve elden geçiren edebî ve edebiyat dışı "çağdaş" anlatılara dikkat kesilir. Öte yandan Bacchilega için tek mesele anlatısal düzenlemelerin nasıl işlediği değildir. Bu yeniden yazımlar esnasında kadına ve hikâyeye dair nasıl imgelerin üretildiği; bu imgelerin hangi anlatısal düzenlemeler ile desteklendiği; ve son olarak bu imgelerin altında öznenin inşasına dair hangi ideolojilerin yatmakta olduğu soruları çalışmanın merkezinde yer alır.

Masal, folklor, edebiyat, feminizm ve postmodernizm çalışmalarına dayanan kitap disiplinlerarası bir bakış açısına sahiptir. Teorik çerçevesini bir varış noktasından ziyade başlangıç olarak gören Bacchilega, kitabını çağdaş masalları anlamak üzere çıktığı bir yolculuk olarak görür. Yolculuğuna ortak olan okuyucudan da ele aldığı konulara aşina olmasını bekler. Bu beklenti, eserde ele alınan kuramsal tartışmaların ve masal incelemelerinin anlaşılmasını yer yer güçleştirir.

Bacchilega, masal alanındaki çalışmaları ile öne çıkan Jack Zipes, Maria Tatar, Ruth B. Bottigheimer gibi eleştirmelerin çalışmalarına sıklıkla atıfta bulunurken; bahsi geçen eleştirmenler gibi, masalın hem özgürleştirici hem de tutucu yönleri olduğunu savunur. Yazar, masallarda pek çok arzunun tatmin aracı olarak yer alan "sihir"in farklı anlatılarda nasıl işlediğini açıklamayı hedefler. Bunun için "sihir"in gücünü eleştirel bir şekilde inceleyen feminist teoriden de faydalanan Bacchilega, "sihir"in masallarda toplumsal cinsiyete dair işletilen bütün hileleri sistematik olarak gizlediğini iddia eder. "Sihir"in barındırdığı paradoksları isimlendirmek 
ve bunların değişken ideolojik etkilerini ifadeye kavuşturmak, Bacchilega'ya göre bir nevi masalın özgürleştirici potansiyelini ortaya çıkarmaktır.

Bacchilega, masalı çocuklar için zararlı rol modeller sunan cinsiyetçi temsillerle dolu anlatılar olarak görmez. Yazara göre masal; halkbilim ve edebiyatın, toplumun ve bireyin, çocukların ve yetişkinlerin, kadın ve kadınların birbiri ile karşılaştığı; birbirleri üzerine düşündüğü, "arada” kalmış bir alandır. Bu görüşten hareketle Bacchilega, eserinde dört bilindik masalı "klasik" ve "çağdaş" yazımları ile birlikte inceler. Her masal incelemesinin ayrı bir bölümü oluşturduğu kitapta, yazar "ikili strateji” olarak isimlendirdiği yaklaşımla masallardaki belirli anlatı bilimsel yönlere dikkat çeker. Yöntem olarak Jacques Derrida ve Helene Cixous'dan beslenen ve dile yapı söküm perspektifinden bakan bir yaklaşımının yanı sıra eleştirel anlatı biliminin imkânlarından da faydalanır. Yazar, $P a$ muk Prenses’te anlatının çerçevesini; Kırmızı Başlıklı Kız'da sesi; Güzel ve Çirkin'de odaklanmayı; Mavi Sakal'da ise faillik meselesini tartışır.

Yazarın, masallara dair okumalarının merkezinde "ayna" metaforu önemli yer tutar. Bacchilega'ya göre, masallardaki denetim "sihirli ayna" ile gerçekleştirilmektedir. "Ayna" hem mimesisi (yansıma) hem kırılmayı (değişen arzular) hem de hikâyenin çerçevelenmesini (hile) kendinde toplamaktadır. İncelediği masallardaki “ayna” kullanımını ideolojik etkisini dönüştürecek şekilde görünür kılmak isteyen yazar, aynı zamanda bu "ayna” imgelerinin "çağdaş" anlatılarda nasıl yeniden üretildiklerine odaklanır.

"Klasik” ve “çağdaş" yorumlara karşılıklı bakan Bacchilega'nın, masalların postmodern versiyonlarının mevcut normları her zaman dönüştüremediğine dikkat çekmesi önemlidir. Toplumsal cinsiyet tartışması bağlamında da kimi postmodern anlatılar klasik masallardaki toplumsal cinsiyet algısını sorgulayabilirken; kimi anlatılar sorgulanmayan bir öznellik veya anlatı modeli içerisinde bu algıyı yeniden üretebilmektedir. Bununla birlikte, Bacchilega'nın postmodern masal uyarlamalarına dair bir diğer önemli tespiti ise postmodern dönüşümlerin "sihir"i ele alış şeklidir. Postmodern yeniden 
yazımlar "sihir”i sıklıkla doğalmış gibi görünen olayların doğallığını bozma stratejisi olarak kullanmaktadır. Toplumsal cinsiyet meselesi de kuşkusuz "doğallık” maskesinin arkasında durmaksızın işleyen unsurların başında gelmektedir. Bacchilega, dört ana masalı incelerken önce her masalın "sihirli" tarihine bakar, ardından postmodern versiyonların "sihir"i nasıl yeniden ele aldığını göstermeye çalışır. Masalların farklı postmodern versiyonlarını incelediği bu süreçte, yeniden yazımların birbirleriyle çakışan yönlerini de görünür kilar.

Bacchilega, Pamuk Prenses masalını incelediği bölümde, toplumsal cinsiyetin anlatılar aracılığı ile yeniden üretimine dikkat kesilir. Yazarın "ayna tutma” olarak isimlendirdiği strateji, özellikle Pamuk Prenses masalında kadını erkek arzusunun yansıması olarak yeniden üretmek için çalışan bir "doğallaştırma” teknolojisidir. Yazar, masalın anlatı çerçevesi içinde "doğal” kadının kristalize edilmiş imgesi olarak gördüğü Pamuk Prenses’i inceleyerek, masal türündeki kadın kahramanların seslerini, bakışlarını ve eylemlerini sınırlandıran anlatı çerçevesine büyüteç tutar.

Bacchilega, çeşitli örnekler üzerinden Pamuk Prenses’teki ayna tutma yöntemlerine ve bunların etkilerine odaklanır. Verdiği örneklerden biri de masalın en bilindik sahnelerinden olan Kraliçe’nin sihirli ayna ile konuşmasıdır. Bu sahnede, Kraliçe sihirli aynaya yaklaşıp dünyanın en güzel kadınının kim olduğunu sorar ve aynada kendisi yerine Pamuk Prenses’i görür. Bacchilega, bu noktada aynanın sesine, bildirdiği yargının gücüne ve dinleyici olarak bizim aynaya olan inancımıza dikkat çeker. Yazara göre bu sahnede, güzelliğin iki kadının değerinin ölçüsü olarak sunulmasına ve bu nedenle iki kadın arasındaki ilişkinin bir düşmanlık ilişkisi olarak tanımlanmasına sebep olan ataerkil bir çerçeveleme söz konusudur (s. 65).

Bacchilega, Pamuk Prenses'te aynadan yansiyan veya aynanın kırarak yansıttığı görüntünün bir "çerçeve" içinde olduğunu unutmamızı sağlayan anlatı kuralını da deşifre eder. Bu kural, çok basit ve güçlü bir stratejidir; dümdüz ifadelerinde toplumsal cinsiyete, sınıfa yahut bireysel yargılara dair hiçbir açık iz bulunmayan dış 
ses yahut gayrişahsî anlatıcı kullanımıdır. "Evvel zaman içinde", "şöyle bir kraliçe varmış", "kraliçe şöyleymiş" gibi ifadeler dış sesin bakışını tek mümkün bakış gibi sunarken, sihirli aynanın her şeyi bilmesini normal kabul eden okuyucu dış sesin söylediği her şeye de inanmaktadır. Birtakım toplumsal gelenekleri sessiz sedasız doğru var sayan bu ayna tutma stratejisi, Bacchilega'ya göre birçok toplumsal norm arasında özellikle toplumsal cinsiyetin yeniden üretilmesini sağlar. Pamuk Prenses’i güzelliğin ve acının imgesi; "ezilen masum kadın kahraman” olarak çerçeveleyip donduran da yine bu stratejidir.

Bacchilega'nın incelediği postmodern yeniden yazımlar, $\mathrm{Pa}$ muk Prenses ile inşa edilen "masum kadın" temsilinin sahip olduğu gücü kabul ederek işe başlar. Fakat bu güce dikkat çekmekteki amaçları, Bacchilega'nın ifade ettiği üzere, onu yinelemek ve güncellemekten ziyade, ideolojik mahiyetini görünür kılarak sorgulamaktır. Bacchilega bu bölümde masalın üç postmodern versiyonunu inceler. Yazara göre, incelediği üst kurmacaların her biri, Pamuk Prenses'in doğallığının masal türünce mevcut, cinsiyetlendirilmiş bir yalan/kurgu olduğunu ifşa etmeye çalışmaktadır. Bunu da “ayna”nın masalın eski anlatımındaki otoritesini görünür kılarak ve ona meydan okuyarak gerçekleştirmektedir.

Yazarın, incelediği ilk postmodern masal Angela Carter'ın 1979 tarihli Kanlı Oda kitabında yer alan "Pamuk Çocuk" adlı metindir. $\mathrm{Bu}$ metinde "ayna" yoktur ama ayna tutmanın mantığını ve stratejileri taklit edilmektedir. Bacchilega, Carter'in mimesisle oynayarak, masaldaki ayna tutma stratejisini, aynanın kusursuzluğunu ve yenilmezliğini sorgulamamızı sağladığını söyler. Bacchilega'nın incelediği ikinci metin ise Robert Coover'ın 1973 tarihli Ölü Kraliçe masalıdır. Cooverda aynanın otoritesini sürdürmeye ayarlı bir strateji olan harici ve görünmez anlatıcı (dış ses) kullanımını reddederek masalı yeniden yazmıştır. Coover, toplumsal cinsiyetin Pamuk Prenses masalındaki yeniden üretimini meraklı bir birinci şahıs anlatıcı kullanmak suretiyle bozmaktadır. Coover'ın masaldaki rolü ile oynadığı Prens, tek boyutlu “düz" bir masal kahramanı değildir, sorgulayıcıdır. Pamuk Prenses'e sorgulayıcı sorular soran Prens, bu 
sayede Prenses'in "dondurulmuş" ve ideolojik olarak çevrelenmiş masum inşasına büyüteç tutmaktadır. Bacchilega'ya göre Coover, Prens'e sordurduğu sorular ile masalın iyi düzenlenmiş kurmaca evrenini de doğal olmaktan çıkarmaktadır. Yazarın bölümde incelediği son eser ise Donald Barthelme’in 1967 tarihli Pamuk Prenses romanıdır. Bacchilega, Barthelme’in metninin Pamuk Prenses'i ses sahibi kılarak onu nesneleştirmekten kaçındığını söyler. Bununla birlikte metnin istemeden de olsa ataerkil senaryo içindeki kadın imgesini sürdürmeye devam ettiğini de ekler.

Bacchilega, Kırmızı Başlıklı Kız masalını incelediği bölümde, bu masalı dinlerken duyduğumuz "ses"lere odaklanır. Yazara göre, Kırmızı Başlıklı Kız masalının folklorik versiyonları, çocukların hinlik yaparak tehlikeyi ve kötülüğü kovma kabiliyetini anlatmasının ötesinde, kadınların sahip olduğu hayatta kalma bilgisinin önemini de vurgulamaktadır. Masalın edebiyat geleneğinde oluşan örneklerinde ise, başkahraman üzerinden kadın temsili cinsiyetli ve kısıtlayıcı bir alana hapsedilmiştir. Bacchilega'nın ifadesi ile, Charles Perrault tarafından 1697'de yayınlanan Kırmızı Başlıklı Kız masalında, masalın folklorik versiyonunda kadına gücünü teslim eden bütün “ses”ler kısılmıştır. Yazara göre, Kırmızı Başlıklı Kız’ın kurt tarafindan cezalandırılması ve kurtarıcısının avcı olması ile, masalda kadınların sınırlarını erkekler çizer hale gelmiştir.

Bacchilega, Kırmızı Başlıklı Kız masalının bu senaryoya sıkıştırılmamasını ister. Ve masalın içindeki harikuladelikleri göstermek üzere, Angela Carter'ın postmodern bir bakışla ele aldığı The Werewolf (Kurt-Adam), The Company of Wolves (Kurtların Arkadaşlığı) ve Wolf-Alice (Kurt-Alice) metinlerine odaklanır. Bacchilega'ya göre Carter'ın masalı yeniden yazma stratejileri anlatıyı dönüştürmüştür. Carter, folklor gelenekleri ve Kırmızı Başlıklı Kız'ın toplumsal tarihiyle girdiği diyalog sayesinde masalın "klasik" versiyonunda kadının gücüne dair bastırılan sesleri duyurmaktadır. Carter'ın bunu yapmasını sağlayan da toplumsal ve metinsel pratikleri incelemek üzere masalın birden fazla versiyonunu kullanmasıdır. Bacchilega, Carter'ın üç “kurt ve kadın” hikâyesini radikal şekilde farklı yazdığını bulgularken; bu hikâyelerin birbirleriyle çelişen yönlerine 
rağmen soykütüksel olarak birbiriyle ilişkili Kırmızı Başlıklı Kız imgelerini meydana getirdiğini söyler.

Bacchilega Güzel ve Çirkin masalını incelediği bölümde, ilk olarak masalın sınıf ve ataerkil düzen ile ilişkisine dikkat çeker. Masalın farklı versiyonlarında, Güzel sınıf mensubiyeti fark etmeksizin kendisini babası için feda ederek evlilik hayatına ataerkil bir çerçeve içinde başlamaktadır. Bacchilega'ya göre baba ve kocanın kâr sağladığı bu değiş tokuşta, Güzel'in kendisini geri plana atması, masaldaki ataerkil çağrının gizlenmesine neden olmaktadır. Bunun yanı sıra, yazara göre Güzel, teslimiyet ve fedakârlığı ile bir başka varlığı, özellikle de toplumsal açıdan tehditkâr bir erkeği dönüştürmeyi başarmasından ötürü pek çok masal kahramanından daha fazlasinı elde etmektedir.

Bacchilega'nın Güzel ve Çirkin masalını incelerken özellikle dikkat çektiği bir diğer nokta ise, Çirkin’in dönüşümüdür. Yazar, Çirkin'in öyküsünün genelde insanları görünüşleriyle yargılamamız gerektiği yönünde bir öğüt olarak okunduğunu belirtirken; anlatının ilettiği mesajların ataerkil vurgulara sahip olduğunu öne sürer. Bacchilega'nın "Çirkin’in dönüşümü gerçekten arzu edilen bir şey midir? Ĕger öyleyse bu kimin arzusudur?” soruları bu bağlamda önemlidir. Bacchilega'ya göre Güzel, anlatıcının "göz"ünün emrindedir. Güzel'e Çirkin’i yaşadığı dönüşüm sonunda yakışıklı bir prens olarak gösteren anlatıcının “göz”ü aynı zamanda Güzel’in bu dönüşüme verdiği tepkiyi de muğlaklaştırmaktadır. Bacchilega, bu noktada masalın gizli ataerkil mesajını deşifre eder. Güzel'in Çirkin ile kurduğu ilişki, “olağandışının” cazibesine sahiptir. Çirkin’in dönüşümü aslında ilişkideki olağandışılığı baltalamaktadır. Bu nedenle, masalın farklı versiyonlarındaki anlatısal düzenlemeler Güzel'in Çirkin’in dönüşümüne verdiği tepkiyi türlü şekillerde hoşnutsuz kılar. Yazara göre, masalda kadın dinleyiciye nihai olarak iletilen mesaj, ilişkideki asıl cazibenin bir erkeği dönüştürebilme ihtimalinin kendisi olduğu yönündedir.

Bacchilega'nın incelediği modern ve postmodern yazarlar da Çirkin'in dönüşümüne dikkat kesilerek Güzel’in prense verdiği muğlak karşılığın altını çizmek ve yorumlamak suretiyle masalın 
metaforik gücünden yararlanmaktadır. Bacchilega masalın dört çağdaş uyarlaması olan Ron Koslow'un çektiği Tv dizisinde, Tanith Lee'nin bilim kurgu hikâyesinde ve Angela Carter'ın iki hikâyesinde masalın toplumsal cinsiyet politikasının izlerini sürerken; özellikle Çirkin'in dönüşümünün anlatılarda nasıl yer aldığına ve bu dönüşümün kadın karakter üzerindeki çarpıcı etkilerine odaklanır.

Bacchilega, son bölümde ise Mavi Sakal masalını inceler. Yazar, sözlü kültür geleneğinde kadının aktifleşmesi, deneyim, akıl ve sevgi kazanmasına dair geçiş örüntülerini ortaya koyan Mavi Sakal masalının, Perrault ve Grimm Kardeşler'in metinlerinde bu özelliğini kaybettiğini belirtir. Bacchilega'nın karşılaştırmalı incelemesi, masalın "klasik" versiyonlarında kadın kahramanın merakı nedeniyle cezalandırıldığını buna karşın Mavi Sakal'ın caniliğinin sürekli göz ardı edildiğini ortaya koyar. Yazar, bu noktada anlatıcının, derlemecinin, editörün yorumlarının masalın esas anlamını belirleyemeyecek ideolojik değişkenler olduğu yönündeki görüşünü dillendirir. Yazara göre Mavi Sakal gibi masallar, zengin ve çeşitlilik barındıran folklorik geleneğe sahiptir ve incelenmeye değerdir.

Bacchilega, bu görüşünden hareketle Mavi Sakal masalının belirli versiyonlarını yeniden yazan Margaret Atwood, Angela Carter, Jane Campion'un postmodern uyarlamalarını inceler. Buna göre, üç yazar da masalın "klasik" versiyonlarının toplumsal cinsiyet dinamiklerini ne şekilde doğallaştırdığını sorgularken; kadın kahramanı da erginleme motifleri ile güçlendirmiştir. Bunun yanı sıra, yazarın incelediği postmodern uyarlamalar, kadın ve erkek kahramanları birbirine eş tutan anlatısal tercihlere sahiptir. Bacchilega bu stratejiyi "çifte faillik" olarak isimlendirir. Yazara göre, postmodern uyarlamalardaki bu strateji Mavi Sakal masalını, hem masalın "klasik" versiyonlarında bulunan "cinsiyetlerin kavgası"ndan uzaklaştırmakta hem de ataerkil politikaların kadınları olduğu kadar erkekleri de baskı altına alan toplumsal bir inşa olarak ifşa etmektedir.

Bacchilega, sıklıkla kadınları karşısına alan ve "ürkütücü" bir masal olarak görülen Mavi Sakal'ın dahi, feminist yeniden yazımlarla toplumsal açıdan anlamlı ve başarılı bir kadınlığa geçiş hikâyesi 
olarak geri kazandırabileceğini savunur. Bir anlamda masal denen bu anlatı odasının, kadınlar için bir hapishane olmak zorunda ol-

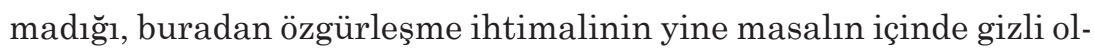
duğu fikrine ulaşır. Masallardaki farklı "ses"leri duyurmak isteyen yazar, postmodern yeniden yazımları da bunu yapma potansiyelleri nedeniyle önemser. Postmodern uyarlamalar, masalların uzun zamandır tedavülde olan anlatı ve toplumsal cinsiyet rollerini ifşa ederken diğer yandan zaman içinde çocuklar için kurumsallaştırılmış masallarda unutulan ihtimalleri de gün yüzüne çıkarmaktadır.

Bacchilega'nın kendi kişisel okuma serüveninin bir sonucu olarak kurguladığg eserinde masallardaki seslere, bakışlara ve eylemlere odaklanırken kadınların masalları yeniden anlamak ve anlatmak üzere giriş̧tikleri bütün çabayı önemsediği görülmektedir. $\mathrm{Bu}$ bağlamda yazarın çabasının da okuyucusuna, hem masallardaki toplumsal cinsiyet ve anlatı stratejilerini anlamaları hem de masalların barındırdığı imkânları görmeleri konusunda rehberlik etmek olduğu söylenebilir. Bacchilega, eserinde klasik ve postmodern masalları incelerken benimsediği karşılaştırmalı okuma ile masala dair arkeolojik bir bakış açısının yanı sıra ilgili okuyucuya zengin bir kaynakça da sunmaktadır. Öte yandan yazarın masalı, hem toplumsal cinsiyete dair işlemekte olan ideolojik düzenlemeler bakımından hem de anlatı bağlamında incelemesinin okuyucunun dikkatini yoğun şekilde talep eden bir metin ortaya çıkardığını da eklemek gerekmektedir. 